\title{
Anisotropic Self-Assembly of Organic-Inorganic Hybrid Microtoroids
}

\author{
Safa'a Al-Rehili, ${ }^{\dagger, \|}$ Karim Fhayli, ${ }^{\dagger, \|}$ Mohamed Amen Hammami, ${ }^{\dagger}$ Basem Moosa, ${ }^{\dagger}$ Sachin Patil, ${ }^{\dagger}$ \\ Daliang Zhang, ${ }^{\ddagger}$ Ohoud Alharbi, ${ }^{\ddagger}$ Mohamed Nejib Hedhili, ${ }^{\ddagger}$ Helmuth Möhwald, ${ }^{\S}$ \\ and Niveen M. Khashab* ${ }^{\dagger}$
}

\author{
${ }^{\dagger}$ Smart Hybrid Materials Laboratory (SHMs), Advanced Membranes and Porous Materials Center, King Abdullah University of \\ Science and Technology (KAUST), Thuwal 23955-6900, Saudi Arabia \\ ${ }^{\ddagger}$ Imaging and Characterization Core Laboratories, King Abdullah University of Science \& Technology (KAUST), Thuwal \\ 23955-6900, Saudi Arabia \\ ${ }^{\S}$ Max-Planck-Institute of Colloids and Interfaces, Am Muehlenberg 1,14476 Potsdam, Germany

\section{Supporting Information}

ABSTRACT: Toroidal structures based on self-assembly of predesigned building blocks are well-established in the literature, but spontaneous self-organization to prepare such structures has not been reported to date. Here, organicinorganic hybrid microtoroids synthesized by simultaneous coordination-driven assembly of amphiphilic molecules and hydrophilic polymers are reported. Mixing amphiphilic molecules with iron(III) chloride and hydrophilic polymers in

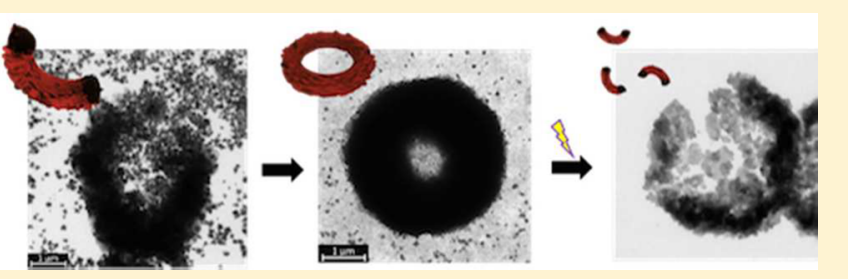
water leads, within minutes, to the formation of starlike nanostructures. A spontaneous self-organization of these nanostructures is then triggered to form stable hybrid microtoroids. Interestingly, the toroids exhibit anisotropic hierarchical growth, giving rise to a layered toroidal framework. These microstructures are mechanically robust and can act as templates to host metallic nanoparticles such as gold and silver. Understanding the nature of spontaneous assembly driven by coordination multiple noncovalent interactions can help explain the well-ordered complexity of many biological organisms in addition to expanding the available tools to mimic such structures at a molecular level.

\section{INTRODUCTION}

Self-assembly provides a general and effective strategy for generating nano- and microstructures. It is one of the most important strategies used in biology for the development of complex, functional structures. The importance of this "bottom-up" approach is that it follows nature's way of building up complexes through self-organization. The arrangement of lipid bilayers ${ }^{1}$ and colloids ${ }^{2}$ and the organization of nucleic acids $^{3}$ are all examples of self-assembly. Non-covalent forces such as metal coordination, ${ }^{4}$ hydrogen bonding, ${ }^{5}$ van der Waals forces, $^{6}$ and hydrophobic ${ }^{7}$ and/or electrostatic interactions ${ }^{8}$ encompass the driving force for the formation of these welldefined structures. Such structures are valuable when employed for biomedical applications, ${ }^{9}$ catalysis, ${ }^{10}$ electronics, ${ }^{11}$ and photonics. $^{12}$ Numerous architectures have been designed through self-assembly, with nanoparticles, ${ }^{13}$ micelles, ${ }^{14}$ vesicles, $^{15}$ and filaments ${ }^{16}$ being the most common.

Recently, a doughnut-shaped or toroidal self-assembled structure generated by a closed plane curve rotating about an axis but not intersecting it, has been reported. ${ }^{17-19}$ Toroids have interesting geometrical properties that are topologically distinctive from those of cylinders, micelles, and spheres. In certain types of viruses, bacteria, and sperm cells, DNA and proteins are organized in a toroidal shape. ${ }^{20-22}$ Most importantly, toroids are found in the self-assembly of transmembrane proteins and lipids such as $\beta$-barrels and $\alpha$ - helical bundles that lead to membrane pore formation. ${ }^{23-26}$ Other published examples of organic toroids include the formation of toroidal nanostructures from the directed selfassembly of block copolymers ${ }^{18,27-29}$ and of monomers with anisotropically predisposed alkene groups as building blocks. ${ }^{30}$ Inorganic toroidal nanocrystals have been synthesized from lithium peroxide, ${ }^{31}$ silica, ${ }^{32}$ titanium disulfide exposed to copper ions, $^{33}$ and magnetite. ${ }^{34}$ Metal-organic framework (MOF) toroids were obtained by metal-organic coordination of oligo(phenylene ethynylene) dicarboxylic acid (OPEA) with zinc acetate $\left(\mathrm{Zn}(\mathrm{OAc})_{2}\right) .{ }^{35}$ Toroids were also reported via the self-assembly of an amphiphilic copolymer (PDMA-rac-PLA) with an organosilicate precursor for preparation of mesoporous films on Si wafers. ${ }^{36,37}$ Although many techniques have been invested in the preparation of such structures, employing predesigned building blocks to direct the assembly was always the indispensable factor.

Coordination-driven assembly constitutes a straightforward approach to spontaneous self-assembly. ${ }^{38-42}$ Some assemblies have interesting structures, such as the hybrid nanoflowers reported by Zare and co-workers. ${ }^{43}$ Spontaneous assembly is also found extensively in pore-forming toxins, where their monomeric forms undergo self-organization based mainly on

Received: September 25, 2016

Published: October 24, 2016 


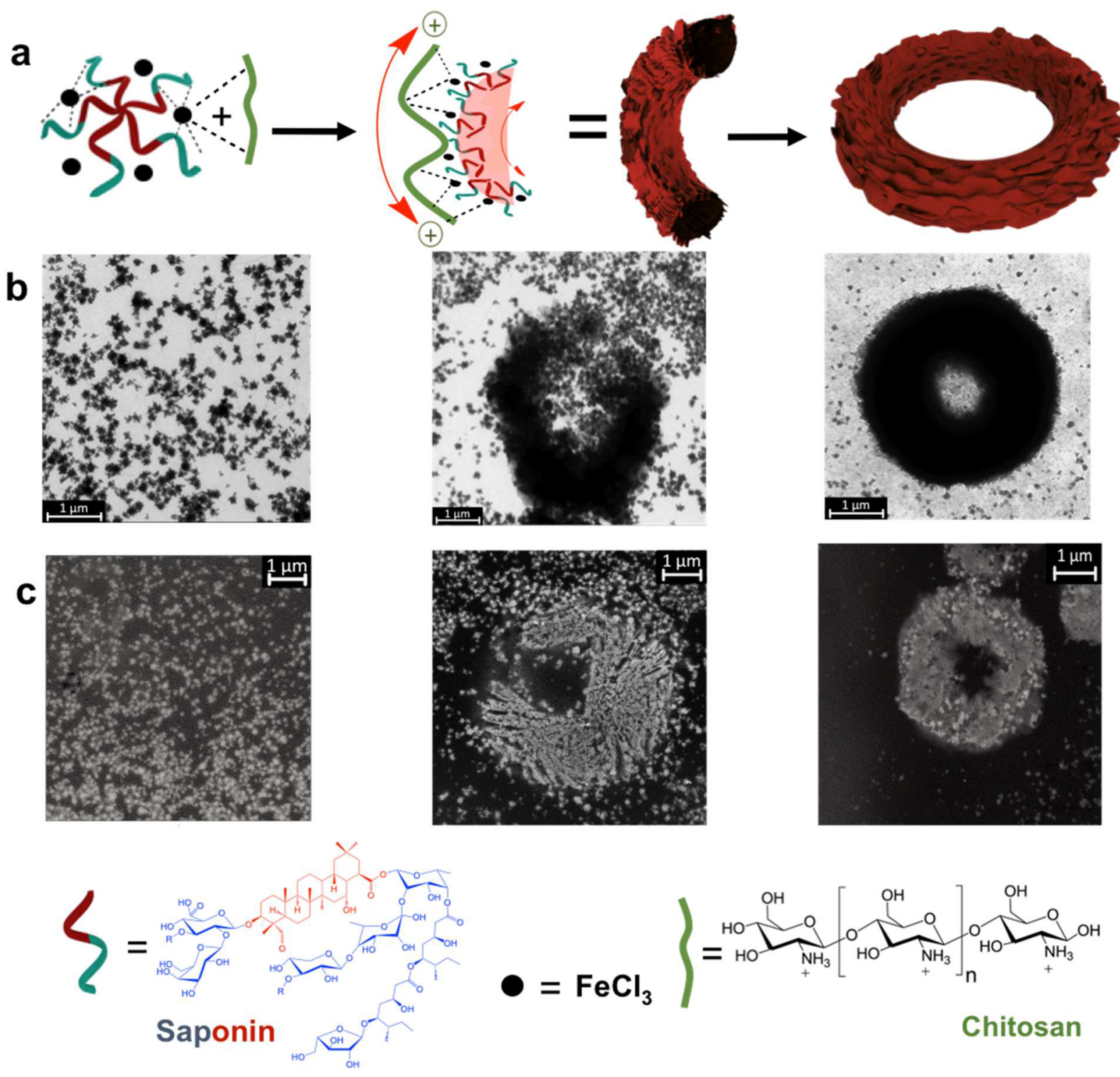

Figure 1. Preparation of hybrid microtoroids. (a) Picture illustrating the steps in the preparation of the microtoroids. (b) TEM and (c) SEM images at each stage of assembly: Adding amphiphilic saponin to an aqueous solution of $\mathrm{FeCl}_{3}$ and chitosan results in the formation of starlike nanostructures; reorganization and growth of the starlike nanostructures mediated by attractive interactions (coordination and hydrophobic interactions) and relief of electrostatic repulsion and steric hindrance results in the formation of toroidal structures.

hydrophobic followed by electrostatic interactions to complete the pore formation. ${ }^{24}$ Using a similar approach, we report the supramolecular preparation of microtoroids by spontaneous self-assembly of amphiphilic molecules (saponin) and a hydrophilic polymer (chitosan) in the presence of iron(III) chloride $\left(\mathrm{FeCl}_{3}\right)$. Coordination-driven assembly of saponin, chitosan, and $\mathrm{FeCl}_{3}$ resulted in the formation of starlike nanostructures within minutes. A spontaneous self-organization of these nanostructures was then prompted to form hybrid microtoroids (Figure 1a). We hypothesize that the assembly occurs as follows: (i) coordination-mediated bonding of iron with hydroxyl groups of chitosan and saponin to form starlike nanostructures; (ii) further coordination of starlike nanostructures aided by the high valency of the multiple edges; (iii) hydrophobic interactions of the lipophilic component of the starlike nanostructures in a "micellar-like" curved assembly; (iv) repulsive electrostatic interactions and steric hindrance of the protonated hydrophilic polymer, finally leading to the toroidal ring closure. The as-prepared toroids were very stable and mechanically robust with sizes ranging from 3.9 to $4.8 \mu \mathrm{m}$. Moreover, the microtoroids showed an anisotropic hierarchical growth affording a layered structure with a height of $1.86 \mu \mathrm{m}$ after $2 \mathrm{~h}$ of assembly. We believe that the starlike coordination complexes provide a location for nucleation of iron chloride crystals and subsequent anisotropic growth. The gap size of the microtoroids can be reproducibly controlled by adjusting the stirring/assembly time. Because of their adjustable nanogap and anisotropic architecture, the microtoroids were used as templates to host metallic nanoparticles ( $\mathrm{Au}$ and $\mathrm{Ag}$ ) for possible future applications in catalysis and separation.

\section{RESULTS AND DISCUSSION}

Preparation and Characterization of Microtoroids. Chitosan has an excellent ability to chelate different transition metal ions due to the presence of hydroxyl groups and extra electron pairs located on nitrogen. ${ }^{44} \mathrm{Fe}$ (III) can efficiently 


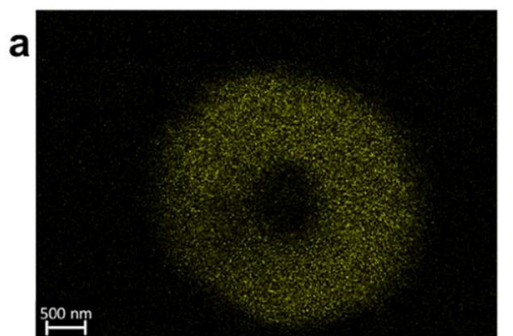

Size Distritution by Volum

d

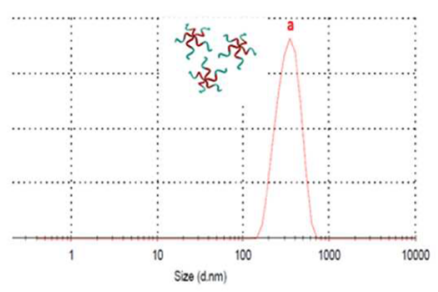

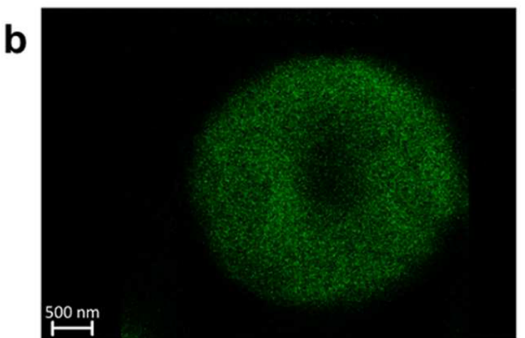

e

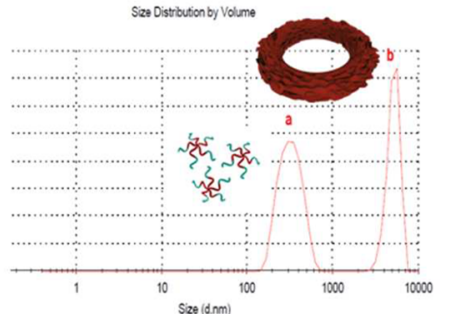

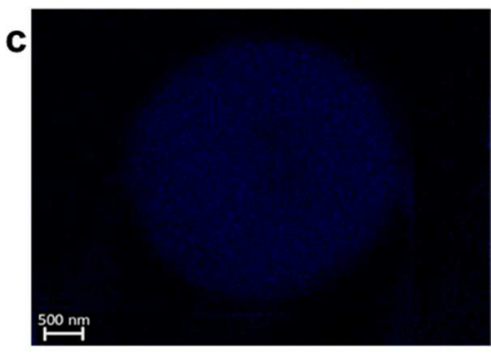

Size Distribution by Volume

f

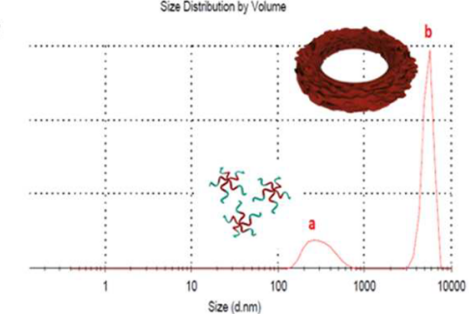

Figure 2. Elemental mapping and monitoring of the formation of microtoroids by DLS. (a-c) Elemental mapping of microtoroids: (a) carbon, (b) oxygen, and (c) iron ions. (d-f) DLS measurements (d) after addition of saponin, chitosan, and $\mathrm{FeCl}_{3}$, where only starlike nanostructures were obtained with an average size of $340 \mathrm{~nm}$; (e) after $2.5 \mathrm{~h}$ of assembly, where starlike nanocrystals and toroids were obtained with average sizes of $326.4 \mathrm{~nm}$ and $5.06 \mu \mathrm{m}$, respectively; and (f) after $4.5 \mathrm{~h}$ of assembly, where toroids were obtained predominantly with an average size of $5.08 \mu \mathrm{m}$.

coordinate chitosan ${ }^{45}$ as well as amphiphilic ligands. ${ }^{46}$ The mode of metal binding in $\mathrm{Fe}$ (III) - chitosan is either penta- or hexacoordinate with nitrogen and/or oxygen ligands, while it is expected that the coordination of iron with the amphiphilic ligand, saponin, is through the hydroxyl groups of sugars. ${ }^{44}$ Saponin $(7 \mathrm{mg})$ was first dissolved in water, followed by dropwise addition of $\mathrm{FeCl}_{3}(61.7 \mu \mathrm{mol})$ and chitosan solution (106.4 $\mu \mathrm{mol}$ of monomer; $20 \mathrm{mg} / \mathrm{mL}$ ). The $\mathrm{pH}$ was kept at 1.8 during the reaction to avoid the formation of iron hydroxides and precipitation of iron chloride. The Fourier transform infrared spectroscopy (FTIR) spectra of chitosan and saponin before and after the formation of the complex were compared (Figure S1). The peak at $1592 \mathrm{~cm}^{-1}$ characteristic of the $-\mathrm{NH}_{2}$ stretching frequency of chitosan disappeared after the formation of the complex, suggesting the implication of $-\mathrm{NH}_{2}$ in the coordination with iron, while the peak at 3459 $\mathrm{cm}^{-1}$ characteristic of the $-\mathrm{OH}$ stretching frequency of saponin relatively decreased because of the restricted movement of these bonds after coordination to iron.

Morphological changes due to the coordination of $\mathrm{FeCl}_{3}$ with saponin and chitosan were closely monitored by transmission electron microscopy (TEM) (Figure 1b) and scanning electron microscopy (SEM) (Figure 1c). Starlike nanostructures with diameters ranging between 191 and 346 $\mathrm{nm}$ were assembled within minutes via coordination bonding. The gradual formation of a curved rodlike microstructure was then monitored. Finally, by continuous assembly and selfassociation of primary nanostructures, the curved rods formed toroids by end-to-end connection. Energy-dispersive X-ray analysis (EDAX) verified the presence of iron ions in the coordination network (Figure S2), and EDAX of the microtoroids showed an increased amount of iron ions in the final structure (Figure S3). Elemental mapping verified the presence of carbon and oxygen in addition to iron in the starlike nanostructures (Figure S4) and microtoroids (Figure $2 \mathrm{a}-\mathrm{c})$. X-ray photoelectron spectroscopy (XPS) analysis was performed to further characterize the elemental composition of the sample. The survey spectrum shows that $\mathrm{Fe}, \mathrm{Cl}, \mathrm{O}, \mathrm{N}$, and $\mathrm{C}$ were present in the microtoroids (Figure S5a). The highresolution spectrum of the $\mathrm{N}$ 1s region from the same sample was also obtained and was fit using two components located at 399.8 and $402.0 \mathrm{eV}$, which correspond to amine and protonated amine $\left(-\mathrm{NH}_{3}^{+}\right)$groups, respectively (Figure $\left.\mathrm{S} 5 \mathrm{~b}\right) .^{47}$ This supports the protonation of chitosan under the acidic reaction conditions. In order to further verify the iron-coordinationdriven assembly, we compared the Fe $2 p$ core-level spectra of $\mathrm{FeCl}_{3}$ and the assembled microtoroids (Figure S5c,d). The Fe $2 \mathrm{p}$ core-level spectrum of $\mathrm{FeCl}_{3}$ was fit using four components located at 711.3, 717.8, 724.9, and $731.2 \mathrm{eV}$. The intense satellite peak at 717.8 is a signature of the $\mathrm{Fe}-\mathrm{Cl}$ bond. The $\mathrm{Fe}$ $2 \mathrm{p}$ core-level spectrum of the microtoroids verifies the presence of iron ions as well as a decrease in the intensity of the $\mathrm{Fe}^{3+}$ satellite, which is an indication of the conversion to mostly $\mathrm{Fe}-$ $\mathrm{O} / \mathrm{OH}$ bonds (Figure S5c,d). ${ }^{48}$ From a comparison of the Xray diffraction (XRD) patterns of the toroids, the saponin-Fe complex, and the chitosan-Fe complex, the characteristic peaks of the toroid spectrum at $58.1^{\circ}, 59.0^{\circ}, 82.6^{\circ}$, and $119.1^{\circ}$ can be assigned to the coordination of iron(III) to chitosan, while the coordination of iron(III) to saponin could additionally contribute to the peak at $48.7^{\circ}$, as the coordination of iron(III) to saponin showed two peaks at $49.1^{\circ}$ and $49.8^{\circ}$ (Figure S6). The strongest broad peaks of the microtoroids observed at $39.3^{\circ}, 40.4^{\circ}$, and $42.0^{\circ}$ correspond to calculated $d$-spacings of 2.3, 2.2, and $2.1 \AA$, which agree with the $d$-spacing values of $\mathrm{FeCl}_{3}$ (PDF main database, tab 01-078-2123).

Monitoring the assembly by dynamic light scattering (DLS) showed that the starlike nanostructures were formed directly after mixing (peak a in Figure 2d). After 2.5 h, a second peak with an average size of $5.06 \mu \mathrm{m}$ was recorded (peak b in Figure $2 \mathrm{e})$. Leaving the solution to stir for extra $2 \mathrm{~h}$ resulted in a decrease in peak a and an increase in peak b (Figure 2f), supporting the rapid assembly of microtoroids. It is worth noting that the microtoroids were uniformly dispersed in solution and that no precipitation was detected through out the assembly. We hypothesize that this is due to the hydrophilic and positively charged nature of the polymer at acidic $\mathrm{pH}$. The broad and bulky XRD peaks support the poor crystallization of these complexes.

Mechanism of Microtoroid Formation. There are probably many interactions contributing to the formation of 

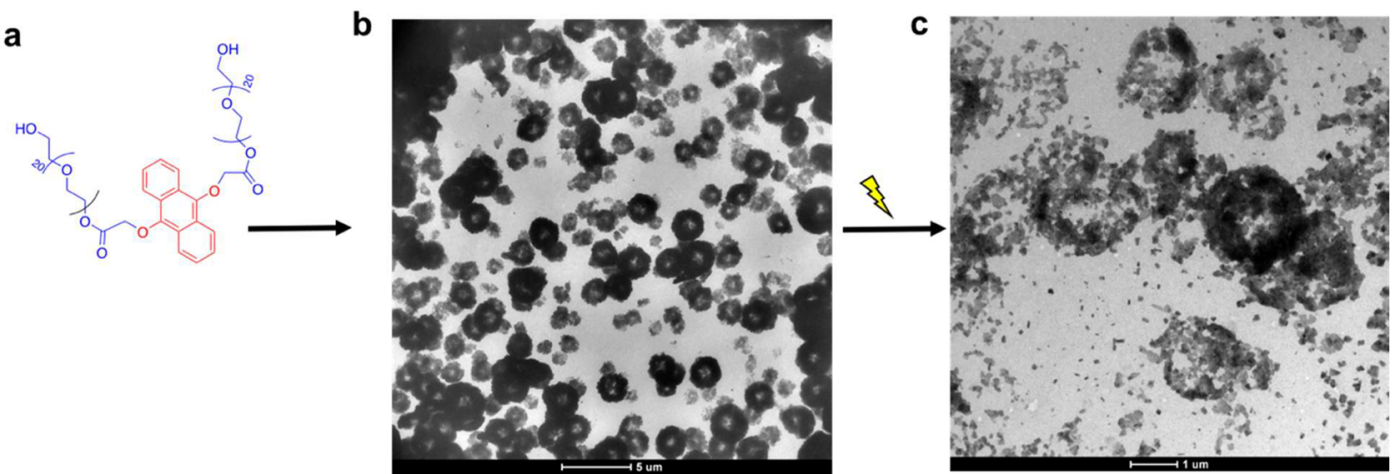

Figure 3. (a) Structure of the light-responsive amphiphilic molecule PEG-anthracene. (b) Formation of microtoroids employing PEG-anthracene as the amphiphilic building block. (c) Degradation of the light-responsive microtoroids upon UV light exposure.

these toroids, as they are made from different materials and with different dimensions and phases. Therefore, we investigated many possible scenarios and deduced that the experimental data primarily support the simplest, most effective and easy to upscale mechanism. Metal coordination is the primary driving force for this assembly, but induction of the interfacial curvature spontaneously without employing "preordered" building blocks is quite remarkable. Lee and coworkers showed that interfacial curvature can be achieved when a bulky, flexible hydrophilic segment is attached to a rigid hydrophobic segment. ${ }^{17}$ As a result, curvature at the interface of the building blocks can be induced to decrease steric repulsion between the bulky hydrophilic segments. In our case, we hypothesize that the positively charged starlike nanostructures $\left(\mathrm{p} K_{\mathrm{a}}\right.$ of chitosan $\left.=6.5\right)$ self-organize to promote favorable interactions predominantly driven by further coordination, hydrophobic interactions, within the lipophilic domains (Figure 1a), and relief of unfavorable steric and electrostatic interactions. This eventually leads to a bent molecular architecture and a high interfacial curvature. To support our proposed assembly mechanism, we replaced saponin with a light-responsive amphiphilic molecule named PEG-anthracene (Figure $3 \mathrm{a}$ and Scheme S1) under the original reaction conditions, which immediately resulted in the formation of microtoroids (Figure $3 \mathrm{~b}$ ). The obtained microtoroids were very stable with an average size of $3 \mu \mathrm{m}$. However, direct UV irradiation of the sample resulted in complete degradation of the microtoroids due to the light-triggered dissociation of the incorporated photoresponsive amphiphile (Figure $3 \mathrm{c}$ and Scheme S1). ${ }^{49}$ Gradual light-induced degradation was monitored as a function of time (Figure S7), which suggests that these structures could be acting as a "glue" to bind the coordination complexes.

Chitosan was then replaced by another hydrophilic polymer, poly( $\mathrm{N}$-isopropylacrylamide) (PNIPAm), that is also protonated under the acidic assembly conditions and can coordinate iron ions. Hollow toroidal structures were successfully and reproducibly prepared under the same experimental conditions, as shown in Figure S8. Employing other types of polymers such as the block copolymer polystyrene-block-poly(4-vinylpyridine) (PS-b-P4VP) did not result in any spontaneous self-assembly.

To develop a deeper insight into the mechanism of toroidal formation, we investigated the effect of the amount of the hydrophilic polymer (chitosan) used on the self-assembled structure. TEM images of the assembly at different ratios of chitosan $\left(R_{\text {chitosan }}\right)$ critically influenced the self-assembled structure (Figure 4$)$. At a low chitosan content $\left(R_{\text {chitosan }}=\right.$
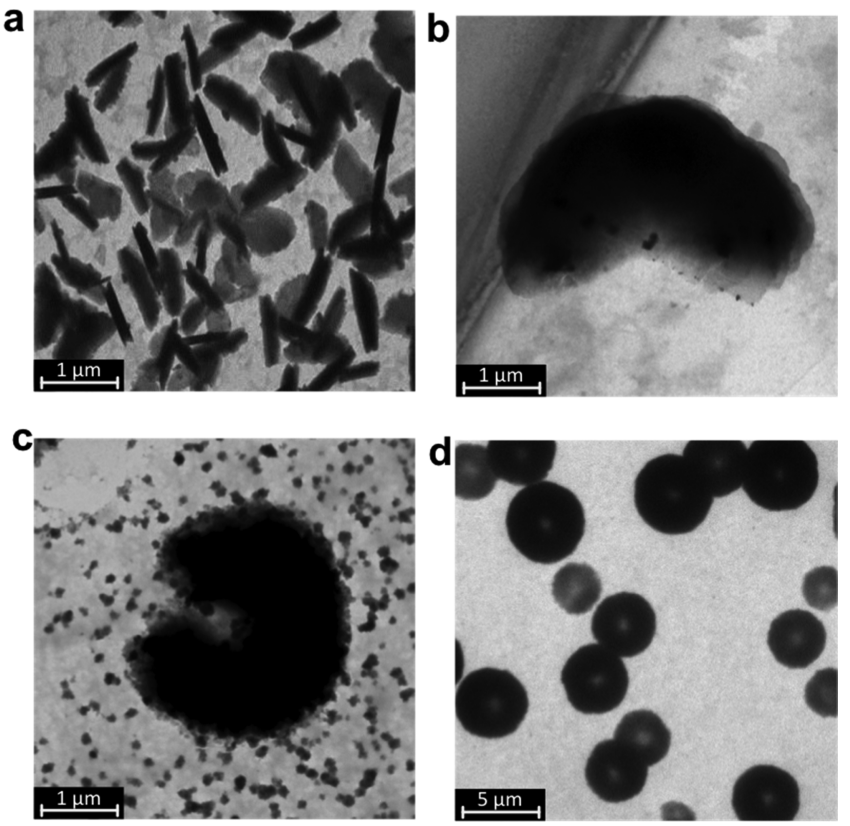

Figure 4. TEM morphologies of microtoroids obtain using various chitosan ratios: (a) $R_{\text {chitosan }}=0.1$; (b) $R_{\text {chitosan }}=0.2$; (c, d) $R_{\text {chitosan }}=$ 0.5 .

0.1 ), a rodlike microstructure with a diameter of $0.19 \mu \mathrm{m}$ and a length of approximately $1.3 \mu \mathrm{m}$ were seen (Figure $4 \mathrm{a}$ ). When $R_{\text {chitosan }}$ was increased to 0.2 , bent rodlike microstructures with a length of $3.3 \mu \mathrm{m}$ were obtained (Figure $4 \mathrm{~b}$ ). Finally, toroid microstructures with an average size of $4.45 \mu \mathrm{m}$ appeared along with curved-rod aggregates when the chitosan content was further increased beyond 0.5 (Figure $4 \mathrm{c}, \mathrm{d}$ ). This further supports our original claim that the metal-coordinated hydrophilic polymer is crucial to evoke nucleation and assembly of the starlike nanostructures. Replacing iron chloride by another trivalent cation salt such as indium chloride or aluminum chloride did not yield toroids (Figure S9a,b, respectively). Employing other transition metal salts such as copper chloride also did not produce toroidal structures (Figure S9c). A possible magnetization effect on the formation was finally tested by using manganese chloride, but only spherical aggregates could be seen by TEM (Figure S9d).

Anisotropic Growth of Microtoroids. Investigating the formation process revealed a hierarchical anisotropic growth of assembled layers (Figure 5a) with a height of $1.86 \mu \mathrm{m}$ after $2 \mathrm{~h}$ of assembly (Figure 5b,c). The anisotropic growth of 

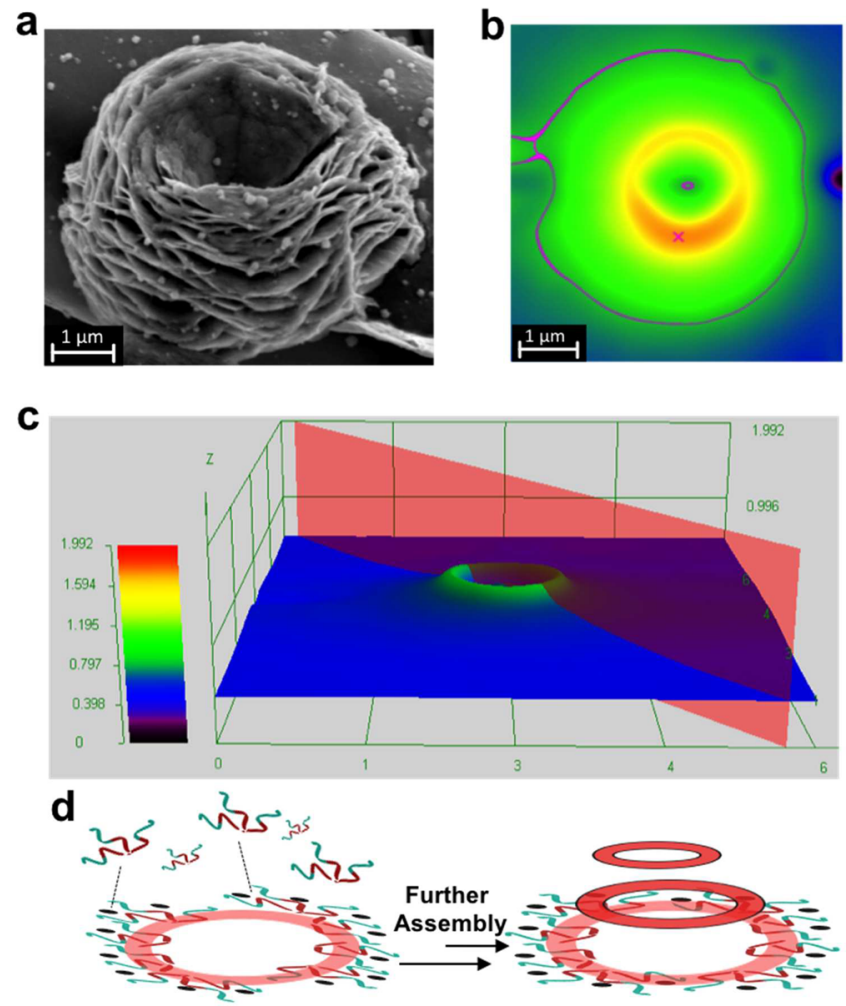

Figure 5. (a) Side-view SEM image of a toroid showing anisotropic growth. (b, c) The topology of a toroid shows a height of $1.65 \mu \mathrm{m}$. (d) Proposed anisotropic growth mechanism.

microtoroids was followed by SEM over the course of $4 \mathrm{~h}$ (Figure S10). The tilted side-view images of the microtoroids show a height of $313 \mathrm{~nm}$ after $30 \mathrm{~min}$, which increased to 520 $\mathrm{nm}, 1.86 \mu \mathrm{m}$, and $3.92 \mu \mathrm{m}$ after 1,2 , and $4 \mathrm{~h}$, respectively. A schematic representation of the proposed assembly mechanism is illustrated in Figure $5 \mathrm{~d}$. It is plausible that the starlike coordination complexes form active nucleation sites for primary crystal growth and thus further coordination. The anisotropic growth originates at the metal ion binding sites, causing the appearance of separate layers.

As $\mathrm{FeCl}_{3}$ can react easily with copper metal of the TEM/ SEM grid to give copper chloride, we furthermore investigated the effect of copper ions on the microtoroid assembly, if any. Replacing $\mathrm{FeCl}_{3}$ with $\mathrm{CuCl}_{2}$ did not produce toroidal structures (Figure S9c). Mixing the two salts also did not yield any clear structures under SEM and TEM. A copper-free grid (Ti/Au/ $\mathrm{Pt} / \mathrm{AuGeNi}$ ) was then employed to check the assembly, and uniformly dispersed microtoroids with an average size of $4 \mu \mathrm{m}$ were seen (Figure S11).

Microtoroid Stability and Intraspace Gap Size. The stability of toroids in their initial solution was studied by TEM. After 1 month of preparation, a persistent toroidal shape was prevalent in the prepared solution at room temperature. Mechanical stirring of the toroidal solution for more than $5 \mathrm{~h}$ led to the disassembly and complete disappearance of the microtoroids. While assessing the stability of toroids, we realized that the stirring time can affect the toroidal intraspace size. Hence, we used the same ratio of our starting materials and stirred the mixture at high speed for $4.5,2$, and $1 \mathrm{~h}$, and then the solutions were left to rest for 2-6 h. The toroidal aggregates had a $0.31 \mu \mathrm{m}$ intraspace size after continuous stirring for $4.5 \mathrm{~h}$ (Figure 6a) compared with $0.65 \mu \mathrm{m}$ after $2 \mathrm{~h}$ (Figure $6 \mathrm{~b}$ ) and $3.11 \mu \mathrm{m}$ after just $1 \mathrm{~h}$ (Figure $6 \mathrm{c}$ ). Increasing the assembly time provides more possibility for anisotropic growth which reaches a maximum after $4.5 \mathrm{~h}$. Therefore, with longer stirring time more compact toroids are formed.

Templates for Metallic Nanoparticles. Because of their complex hierarchal structure and tunable gap, the microtoroids were investigated as templates to host metallic nanoparticles. Such structures could prove feasible in acting as catalytic pockets or selective adsorbents. ${ }^{50,51}$ Therefore, an aqueous solution of gold nanoparticles (AuNPs) was added during the assembly of microtoroids, resulting in uniformly dispersed AuNP-doped microstructures. Elemental mapping confirmed the presence of gold in the entire toroid (Figure 7a). The impregnation of toroids with silver particles was also possible under the same conditions (Figure $7 \mathrm{~b}$ ).

\section{CONCLUSIONS}

Organic-inorganic hybrid microtoroids with anisotropic growth were produced by spontaneous self-organization of coordination complexes comprising $\mathrm{FeCl}_{3}$, amphiphilic molecules, and protonated hydrophilic polymers. These microstructures were prepared by coordination and multiple noncovalent interactions, including micellar hydrophobic interactions. We hypothize that the coordination complexes induce nucleation and subsequent growth to give an anisotropic layered structure. This work provides new insights on the role of multiple non-covalent interactions in directing the preparation of new hybrid structures with complex molecular architecture.

\section{EXPERIMENTAL SECTION}

Materials. The mixtures were prepared using medium-molecularweight chitosan (MW $=190000-310000 ;$ Aldrich $), \operatorname{poly}(N$ isopropylacrylamide) (PNIPAm) $\left(M_{n}=560000\right.$; Polymer Source,
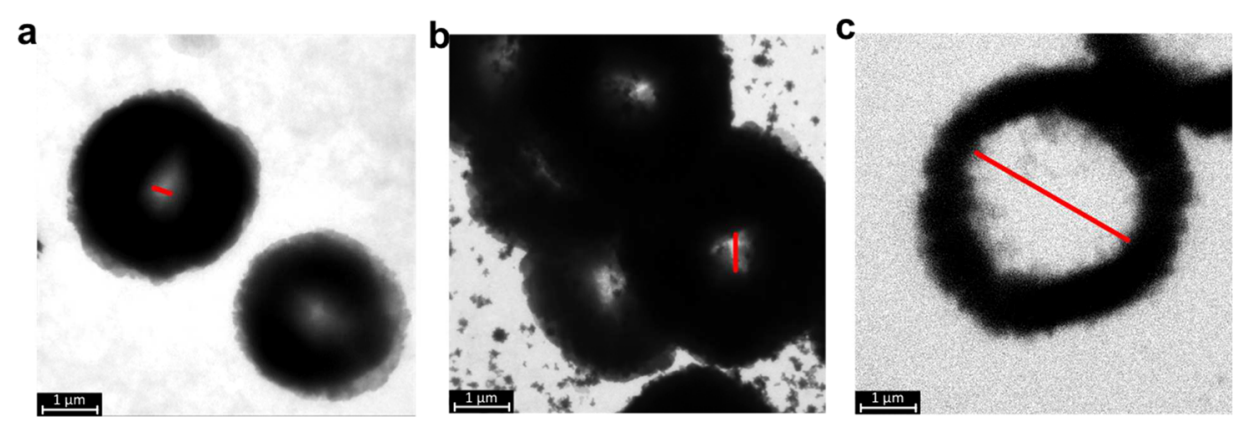

Figure 6. TEM morphologies of microtoroids with different gap sizes: (a) $0.31 \mu \mathrm{m}$; (b) $0.65 \mu \mathrm{m}$; (c) $3.11 \mu \mathrm{m}$. 

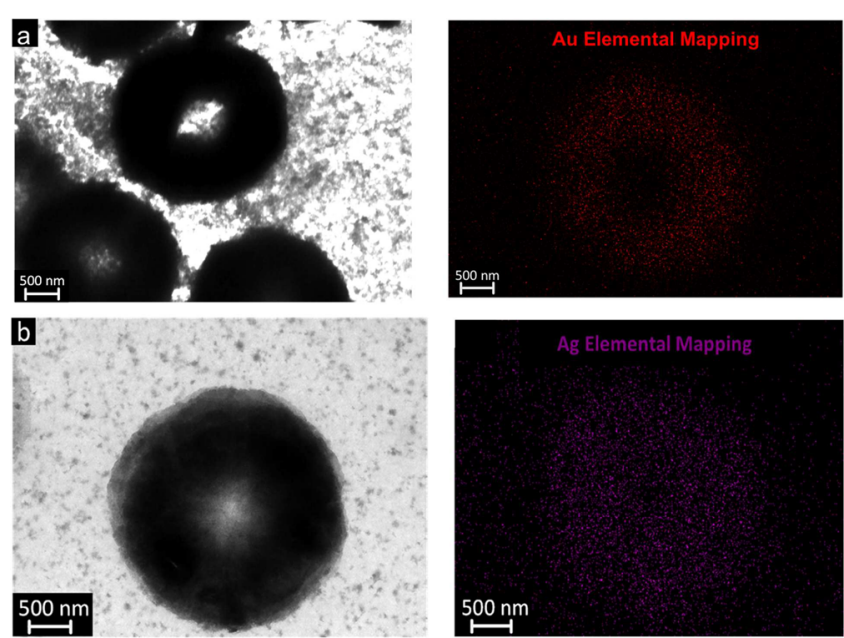

Figure 7. (a) Elemental mapping SEM-EDX of Au after doping microtoroids in gold nanoparticles solution. (b) Elemental mapping SEM-EDX of $\mathrm{Ag}$ after doping microtoroids in silver nanoparticles solution.

Inc.), saponin (Alfa Aesar), anhydrous iron(III) chloride (Riedel-de Haën), and glacial acetic acid (Panreac Sintesis). All of these reagents were used without further purification. The deionized water utilized in the experiments was purified by a Milli-Q system (Millipore).

Preparation of Microtoroids Using Chitosan. A $1 \mathrm{~mL}$ aliquot of amphiphilic solution $(7 \mathrm{mg} / \mathrm{mL})$ dissolved in Milli- $Q$ water was transferred to a vial fitted with a magnetic stirring bar, after which 0.5 $\mathrm{mL}$ of iron(III) chloride solution $(20 \mathrm{mg} / \mathrm{mL})$ was slowly added dropwise under stirring. Finally, $1 \mathrm{~mL}$ of a freshly prepared stock solution of polymeric chitosan, corresponding to $R_{\text {chitosan }}=0.74(20$ $\mathrm{mg} / \mathrm{mL}$, dissolved in $1 \%(\mathrm{v} / \mathrm{v})$ acetic acid for $2 \mathrm{~h}$ ), was added to the stirred solution. The mixture was allowed to self-assemble under a stirring speed of $250 \mathrm{rpm}$ for $4.5 \mathrm{~h}$, and the $\mathrm{pH}$ was kept at 1.8 . $R_{\text {chitosan }}$ is defined as the ratio of the weight of chitosan polymer to the total weight of saponin and chitosan. To obtain a rodlike microstructure, $38.5 \mu \mathrm{L}$ of chitosan was added, corresponding to $R_{\text {chitosan }}=0.1$. To obtain separated rodlike microstructures, $87.5 \mu \mathrm{L}$ of chitosan was added, corresponding to $R_{\text {chitosan }}=0.2$.

Preparation of Microtoroids Using PNIPAm. Similarly, $1 \mathrm{~mL}$ of saponin solution $(7 \mathrm{mg} / \mathrm{mL})$ in Milli-Q water was transferred to a vial fitted with a magnetic stirring bar, and $0.5 \mathrm{~mL}$ of iron(III) chloride solution $(20 \mathrm{mg} / \mathrm{mL})$ was slowly added dropwise under stirring. Finally, $1 \mathrm{~mL}$ of a freshly prepared solution of PNIPAm in Milli-Q water $(20 \mathrm{mg} / \mathrm{mL}$; solubilized for several hours in Milli-Q water) was added to the stirred solution. The mixture was allowed to self-assemble under a stirring speed of $250 \mathrm{rpm}$ for $6.5 \mathrm{~h}$.

Synthesis of Light-Responsive Microtoroids. To a solution of medium-molecular-weight chitosan polymer (monomer MW $=188 \mathrm{~g}$ / mol; $0.106 \mathrm{mmol}, 20 \mathrm{mg}$ ) in $1 \mathrm{~mL}$ of Milli-Q water (1\% acetic acid) was added $0.5 \mathrm{~mL}$ of a solution of iron(III) chloride $(162 \mathrm{~g} / \mathrm{mol} ; 61.7$ $\mu \mathrm{mol}, 10 \mathrm{mg}$ ) followed by dropwise addition of a $1 \mathrm{~mL}$ PEGanthracene solution $(9 \mathrm{mg})$. The mixture was stirred at room temperature at a low stirring speed $(250 \mathrm{rpm})$ for $4 \mathrm{~h}$.

Synthesis of Gold-Decorated Microtoroids. Gold nanoparticles were produced by dissolving chloroauric acid $\left(\mathrm{HAuCl}_{4}\right)\left(1.7 \mathrm{mg}, 10^{-4}\right.$ $\mathrm{M})$ in $50 \mathrm{~mL}$ of Milli- $\mathrm{Q}$ water and then reducing it with $5 \mathrm{mg}$ of sodium borohydride $\left(\mathrm{NaBH}_{4}\right)$ in an ice bath followed by dialysis in Milli-Q water (molecular weight cutoff $=12-14 \mathrm{kDa}$ ). To functionalize toroids with gold nanoparticles, $200 \mu \mathrm{L}$ of the previously synthesized solution and the other components of the toroid mixture were added in the following order: saponin, iron(III) chloride, chitosan, and finally AuNPs. The mixture was allowed to self-assemble under a stirring speed of $250 \mathrm{rpm}$ for $4.5 \mathrm{~h}$.

Synthesis of Silver-Decorated Toroids. Following the same procedure as described above, silver nitrate $\left(\mathrm{AgNO}_{3}\right)\left(0.85 \mathrm{mg}, 10^{-4}\right.$
M) was reduced with $5 \mathrm{mg}$ of $\mathrm{NaBH}_{4}$ and then functionalized with toroids.

Transmission Electron Microscopy. TEM was used to observe the self-assembled structures using a Tecnai bio T12 microscope operating at an accelerating voltage of $120 \mathrm{kV}$ and equipped with an EDAX accessory. A drop of mixture solution was placed directly on the grid and then dried at room temperature. Selected-area electron diffraction (SAED) was performed on the same TEM machine.

Scanning Electron Microscopy. Surface profiles of the aggregates were analyzed by SEM using a Nova Nano microscope with an accelerating voltage of $5 \mathrm{kV}$. A drop of mixture solution was placed directly on a carbon-coated copper grid and dried at room temperature. Before the analysis, samples were sputtered with iridium $(2 \mathrm{~nm})$. It is worth noting that no defined toroidal structures could be seen when gold grids were employed. This could be explained in terms of the importance of the metallic grid surface for electrical bias purposes, which helps in reducing SEM charging. This could subsequently affect the stability of the toroids, so a copper surface could promote or stabilize the assembly.

Dynamic Light Scattering. The aggregate sizes were examined using a Zetasizer Nano ZS instrument (Malvern). In all of the DLS analyses, three measurements were performed, and the values were then averaged.

Fourier Transform Infrared Spectroscopy. The spectra were recorded with a Nicolet iS10 spectrometer (Thermo Scientific) in $\mathrm{KBr}$ pellets.

X-ray Photoelectron Spectroscopy. XPS studies were carried out on a Kratos Axis Ultra DLD spectrometer equipped with a monochromatic $\mathrm{Al} \mathrm{K} \alpha \mathrm{X}$-ray source $(h \nu=1486.6 \mathrm{eV})$ operating at 150 $\mathrm{W}$, a multichannel plate, and delay line detector under a vacuum of 1.0 $\times 10^{-9}$ Torr. Measurements were performed in hybrid mode using electrostatic and magnetic lenses, and the takeoff angle (i.e., the angle between the sample surface normal and the electron optical axis of the spectrometer) was $0^{\circ}$. All of the spectra were recorded using an aperture slot with dimensions of $300 \mu \mathrm{m} \times 700 \mu \mathrm{m}$. The survey and high-resolution spectra were collected at fixed analyzer pass energies of 160 and $20 \mathrm{eV}$, respectively. Samples were mounted in floating mode in order to avoid differential charging. Charge neutralization was required for all of the samples. Binding energies were referenced to the $\mathrm{C}$ 1s peak (set at $284.8 \mathrm{eV}$ ) of the $\mathrm{sp}^{3}$-hybridized $(\mathrm{C}-\mathrm{C})$ carbon from saponin and chitosan. The data were analyzed with commercially available software (CasaXPS).

Powder X-ray Diffraction. XRD was performed on Bruker D8 Advance diffractometer $(40 \mathrm{kV}, 40 \mathrm{~mA}, 1.54058 \mathrm{~nm})$. A $2 \mathrm{~mL}$ aliquot of the solution was freeze-dried and analyzed at low scan speed (increment, 0.06; scan type, Locked Coupled; Discr. Lower Level, 0.18 $\mathrm{V})$.

Steady-State Photoluminescence (PL). The PL spectra were recorded with a LabRAM ARAMIS (Horiba Scientific) microphotoluminescence $(\mu \mathrm{PL})$ spectroscopy system at room temperature. All of the samples were excited with a $475 \mathrm{~nm}$ laser excitation source. To achieve reliability, measurements were collected at five different positions for each sample. The results shown are the averaged spectra.

\section{ASSOCIATED CONTENT}

\section{S Supporting Information}

The Supporting Information is available free of charge on the ACS Publications website at DOI: 10.1021/jacs.6b10080.

Characterization data (FTIR, EDAX, XPS, XRD, TEM, and SEM) and synthesis and degradation of the PEGanthracene precursor (PDF)

\section{AUTHOR INFORMATION}

\section{Corresponding Author}

*Niveen.Khashab@kaust.edu.sa

\section{Author Contributions}

${ }$ S.A.-R. and K.F. contributed equally. 


\section{Notes}

The authors declare no competing financial interest.

\section{ACKNOWLEDGMENTS}

This work was supported by King Abdullah University of Science and Technology (KAUST). We thank Dr. Dalaver Anjum and Dr. Rachid Sougrat of the KAUST Imaging and Characterization Core Lab for helpful discussions.

\section{REFERENCES}

(1) Israelachvili, J. N.; Mitchell, D. J.; Ninham, B. W. J. Chem. Soc., Faraday Trans. 2 1976, 72, 1525.

(2) Stratford, K.; Henrich, O.; Lintuvuori, J. S.; Cates, M. E.; Marenduzzo, D. Nat. Commun. 2014, 5, 3954.

(3) Lee, H.; Lytton-Jean, A. K. R.; Chen, Y.; Love, K. T.; Park, A. I.; Karagiannis, E. D.; Sehgal, A.; Querbes, W.; Zurenko, C. S.; Jayaraman, M.; Peng, C. G.; Charisse, K.; Borodovsky, A.; Manoharan, M.; Donahoe, J. S.; Truelove, J.; Nahrendorf, M.; Langer, R.; Anderson, D. G. Nat. Nanotechnol. 2012, 7, 389.

(4) Tanaka, K.; Clever, G. H.; Takezawa, Y.; Yamada, Y.; Kaul, C.; Shionoya, M.; Carell, T. Nat. Nanotechnol. 2006, 1, 190.

(5) Slater, A. G.; Perdigao, L. M. A.; Beton, P. H.; Champness, N. R. Acc. Chem. Res. 2014, 47, 3417.

(6) Tahara, K.; Lei, S. B.; Adisoejoso, J.; De Feyter, S.; Tobe, Y. Chem. Commun. 2010, 46, 8507.

(7) Garde, S. Nature 2015, 517, 277.

(8) Hu, C. Y.; Lin, K. Q.; Wang, X. L.; Liu, S. J.; Yi, J.; Tian, Y.; Wu, B. H.; Chen, G. X.; Yang, H. Y.; Dai, Y.; Li, H.; Zheng, N. F. J. Am. Chem. Soc. 2014, 136, 12856.

(9) Gu, L.; Faig, A.; Abdelhamid, D.; Uhrich, K. Acc. Chem. Res. 2014, 47, 2867.

(10) Wang, Q. Q.; Gonell, S.; Leenders, S. H. A. M.; Durr, M.; Ivanovic-Burmazovic, I.; Reek, J. N. H. Nat. Chem. 2016, 8, 225.

(11) Stavila, V.; Talin, A. A.; Allendorf, M. D. Chem. Soc. Rev. 2014, 43, 5994.

(12) von Freymann, G.; Kitaev, V.; Lotsch, B. V.; Ozin, G. A. Chem. Soc. Rev. 2013, 42, 2528.

(13) Simon, U. Nat. Mater. 2013, 12, 694.

(14) Qiu, H. B.; Gao, Y.; Boott, C. E.; Gould, O. E. C.; Harniman, R. L.; Miles, M. J.; Webb, S. E. D.; Winnik, M. A.; Manners, I. Science 2016, 352, 697.

(15) Tanner, P.; Baumann, P.; Enea, R.; Onaca, O.; Palivan, C.; Meier, W. Acc. Chem. Res. 2011, 44, 1039.

(16) Palmer, L. C.; Leung, C. Y.; Kewalramani, S.; Kumthekar, R.; Newcomb, C. J.; Olvera de la Cruz, M.; Bedzyk, M. J.; Stupp, S. I. J. Am. Chem. Soc. 2014, 136, 14377.

(17) Kim, Y.; Li, W.; Shin, S.; Lee, M. Acc. Chem. Res. 2013, 46, 2888.

(18) Cui, H. G.; Chen, Z. Y.; Wooley, K. L.; Pochan, D. J. Soft Matter 2009, 5, 1269.

(19) Djalali, R; Samson, J.; Matsui, H. J. Am. Chem. Soc. 2004, 126, 7935

(20) Brewer, L. R. Integr Biol-Uk 2011, 3, 540.

(21) Bera, A.; Perkins, E. M.; Zhu, J.; Zhu, H.; Desai, P. PLoS One 2014, 9, e104640.

(22) Kovall, R.; Matthews, B. W. Science 1997, 277, 1824.

(23) Mueller, M.; Grauschopf, U.; Maier, T.; Glockshuber, R.; Ban, N. Nature 2009, 459, 726.

(24) Benke, S.; Roderer, D.; Wunderlich, B.; Nettels, D.; Glockshuber, R.; Schuler, B. Nat. Commun. 2015, 6, 6198.

(25) Kim, J. K.; Lee, E.; Huang, Z. G.; Lee, M. J. Am. Chem. Soc. 2006, 128, 14022.

(26) Li, W.; Li, J. F.; Lee, M. Chem. Commun. 2013, 49, 8238.

(27) Ni, B.; Huang, M. J.; Chen, Z. R.; Chen, Y. C.; Hsu, C. H.; Li, Y. W.; Pochan, D.; Zhang, W. B.; Cheng, S. Z. D.; Dong, X. H. J. Am. Chem. Soc. 2015, 137, 1392.

(28) Huang, H.; Chung, B.; Jung, J.; Park, H. W.; Chang, T. Angew. Chem., Int. Ed. 2009, 48, 4594.
(29) Chen, L.; Jiang, T.; Lin, J. P.; Cai, C. H. Langmuir 2013, 29, 8417.

(30) Lee, J.; Baek, K.; Kim, M.; Yun, G.; Ko, Y. H.; Lee, N. S.; Hwang, I.; Kim, J.; Natarajan, R.; Park, C. G.; Sung, W.; Kim, K. Nat. Chem. 2014, 6, 97.

(31) Mitchell, R. R.; Gallant, B. M.; Shao-Horn, Y.; Thompson, C. V. J. Phys. Chem. Lett. 2013, 4, 1060.

(32) Iskandar, F.; Mikrajuddin; Okuyama, K. Nano Lett. 2001, 1, 231.

(33) Jeong, S.; Han, J. H.; Jang, J. T.; Seo, J. W.; Kim, J. G.; Cheon, J. J. Am. Chem. Soc. 2011, 133, 14500.

(34) Isojima, T.; Suh, S. K.; Vander Sande, J. B.; Hatton, T. A. Langmuir 2009, 25, 8292.

(35) Suresh, V. M.; George, S. J.; Maji, T. K. Adv. Funct. Mater. 2013, 23, 5585 .

(36) Choi, J.; Hermans, T. M.; Lohmeijer, B. G. G.; Pratt, R. C.; Dubois, G.; Frommer, J.; Waymouth, R. M.; Hedrick, J. L. Nano Lett. 2006, 6, 1761.

(37) Hermans, T. M.; Choi, J.; Lohmeijer, B. G. G.; Dubois, G.; Pratt, R. C.; Kim, H. C.; Waymouth, R. M.; Hedrick, J. L. Angew. Chem., Int. Ed. 2006, 45, 6648 .

(38) Wang, W.; Wang, Y.-X.; Yang, H.-B. Chem. Soc. Rev. 2016, 45, 2656.

(39) Xu, L.; Wang, Y.-X.; Chen, L.-J.; Yang, H.-B. Chem. Soc. Rev. 2015, 44, 2148.

(40) Chen, L.; Chen, Q.; Wu, M.; Jiang, F.; Hong, M. Acc. Chem. Res. 2015, 48, 201.

(41) Cook, T. R.; Vajpayee, V.; Lee, M. H.; Stang, P. J.; Chi, K.-W. Acc. Chem. Res. 2013, 46, 2464.

(42) Cook, T. R.; Zheng, Y.-R.; Stang, P. J. Chem. Rev. 2013, 113, 734.

(43) Ge, J.; Lei, J. D.; Zare, R. N. Nat. Nanotechnol. 2012, 7, 428.

(44) Schlamp, S.; Thoma, P.; Weber, B. Chem. - Eur. J. 2014, 20, 6462.

(45) Somsook, E.; Hinsin, D.; Buakhrong, P.; Teanchai, R; Mophan, N.; Pohmakotr, M.; Shiowatana, J. Carbohydr. Polym. 2005, 61, 281.

(46) Giacalone, G.; Hillaireau, H.; Capiau, P.; Chacun, H.; Reynaud, F.; Fattal, E. J. Controlled Release 2014, 194, 211.

(47) Liao, B.; Long, P.; He, B.; Yi, S.; Ou, B.; Shen, S.; Chen, J. J. Mater. Chem. C 2013, 1, 3716.

(48) Grosvenor, A. P.; Kobe, B. A.; Biesinger, M. C.; McIntyre, N. S. Surf. Interface Anal. 2004, 36, 1564.

(49) Patil, S.; Moosa, B.; Alsaiari, S.; Alamoudi, K.; Alshamsan, A.; AlMalik, A.; Adil, K.; Eddaoudi, M.; Khashab, N. M. Chem. - Eur. J. 2016, 22, 13789.

(50) Iyer, K. S.; Saunders, M.; Becker, T.; Evans, C. W.; Raston, C. L. J. Am. Chem. Soc. 2009, 131, 16338.

(51) Doyle, L.; Hallinan, J.; Bolduc, J.; Parmeggiani, F.; Baker, D.; Stoddard, B. L.; Bradley, P. Nature 2015, 528, 585. 